\title{
Brisk bleeding after gastric lesion biopsy - possible needle tract seeding after endoscopic ultrasound-guided fine-needle biopsy of a pancreatic metastasis from renal cell carcinoma
}

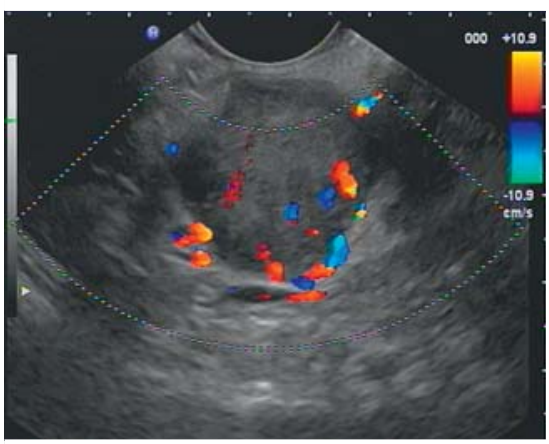

> Fig. 1 Color-coded duplex endoscopic ultrasound (EUS) prior to EUS-guided fine-needle biopsy showed a hypoechoic mass with increased vascularity in the pancreatic body.

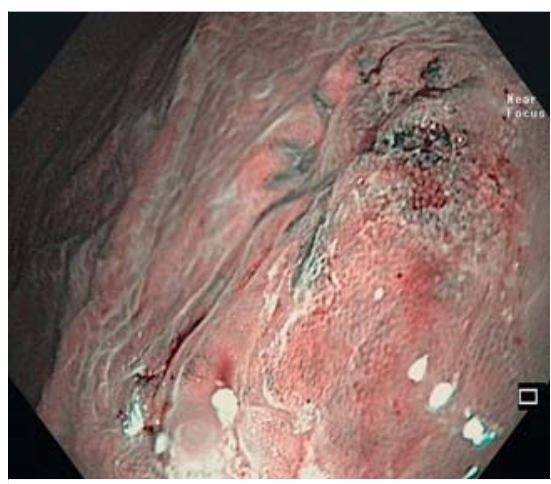

-Fig. 2 Narrow-band imaging of the mucosal lesion on the posterior gastric wall presented an aberrant vascular pattern.

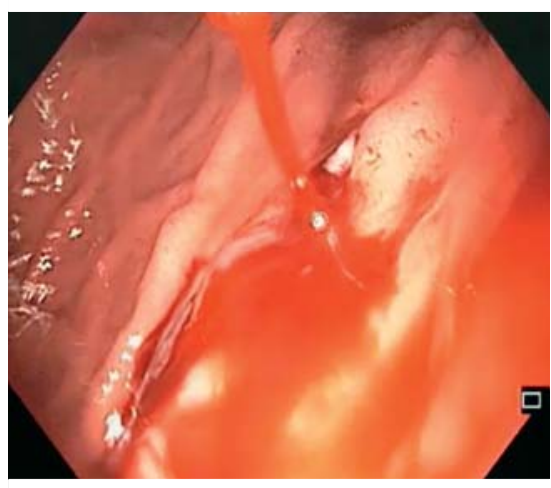

- Fig. 3 Gastroscopic image of the arterial bleeding after forceps biopsy.

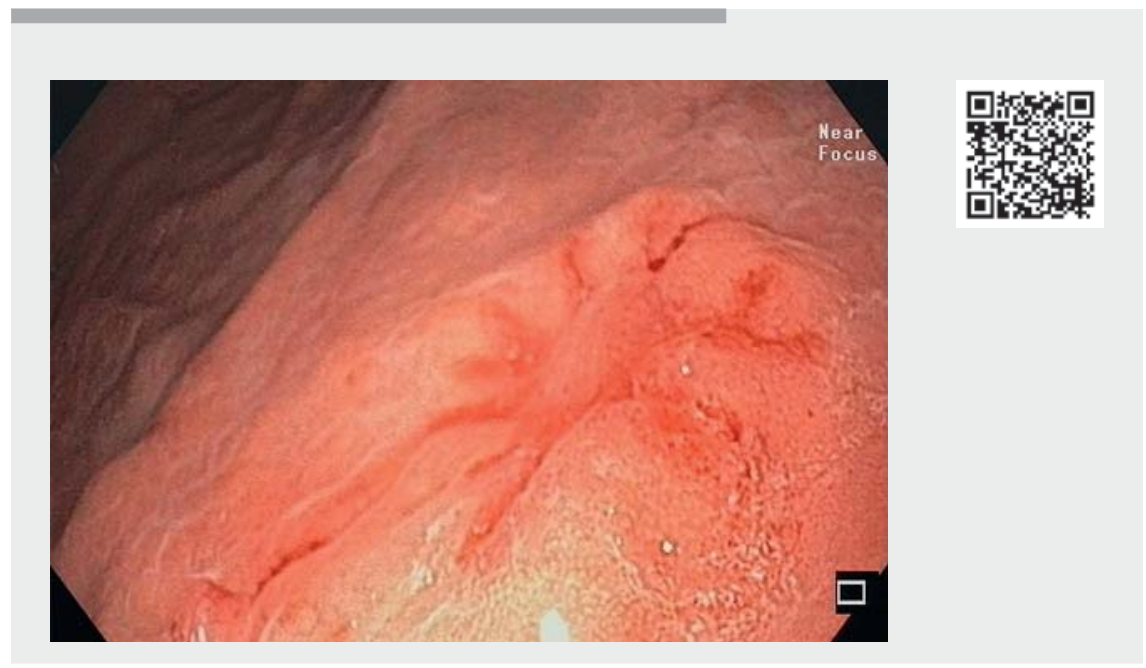

$\checkmark$ Video 1 Endoscopic ultrasound (EUS)-guided biopsy and bleeding management in a case of possible needle track seeding after EUS-guided fine-needle biopsy of pancreatic metastasis from renal cell carcinoma.

A 62-year-old patient had undergone left-sided partial nephrectomy due to renal cell carcinoma. The postoperative tumor classification was pT1a, pNx, LO, VO, G2, RO.

The patient presented 6 years later with abdominal pain and unintended weight loss. Computed tomography (CT) imaging indicated multiple pancreatic lesions, therefore an endoscopic ultrasound (EUS)-guided transgastric fine-needle biopsy was performed using the Procore 19G needle (Cook Medical, Limerick, Ireland) ( Fig.1). Recurrence of the renal cell carcinoma was diagnosed. The tumor board decided for a pancreatectomy with splenectomy as there were no further metastases.

The patient was readmitted 6 months later because of neck swelling. The CT scan revealed a nodular goiter and a pneumomediastinum of unknown origin. Subsequent bronchoscopy and gastroscopy excluded perforation as the cause of the pneumomediastinum, which remained unclear. However, a mucosal lesion presenting an aberrant vascular pattern was detected on the posterior wall of the gastric body ( Fig. 2 ). Forceps biopsy led to arterial bleeding (> Fig.3). An over-the-scope-clip (OTSC; Ovesco, Tübingen, Germany) was applied to control the bleeding ( $\triangleright$ Video 1 ). Histological examination showed a renal cell carcinoma underneath the gastric mucosa ( $\triangleright$ Fig.4). Since the location of the gastric lesion corresponded to the fine-needle biopsy site, it was most likely the procedure had caused needle tract seeding to the gastric wall. Because fine-needle biopsy of the nodular goiter also revealed metastases of the renal cell carcinoma, a thyroidectomy and gastric wedge-resection were performed (> Fig. 5).

Pancreatic metastases are rare, with a reported incidence varying from $1.6 \%$ to $11 \%$ [1]. The most common metastasis to the pancreas is renal cell carcinoma [2]. EUS-guided fine-needle biopsy is considered a safe technique with few adverse events. However, needle track seeding, 


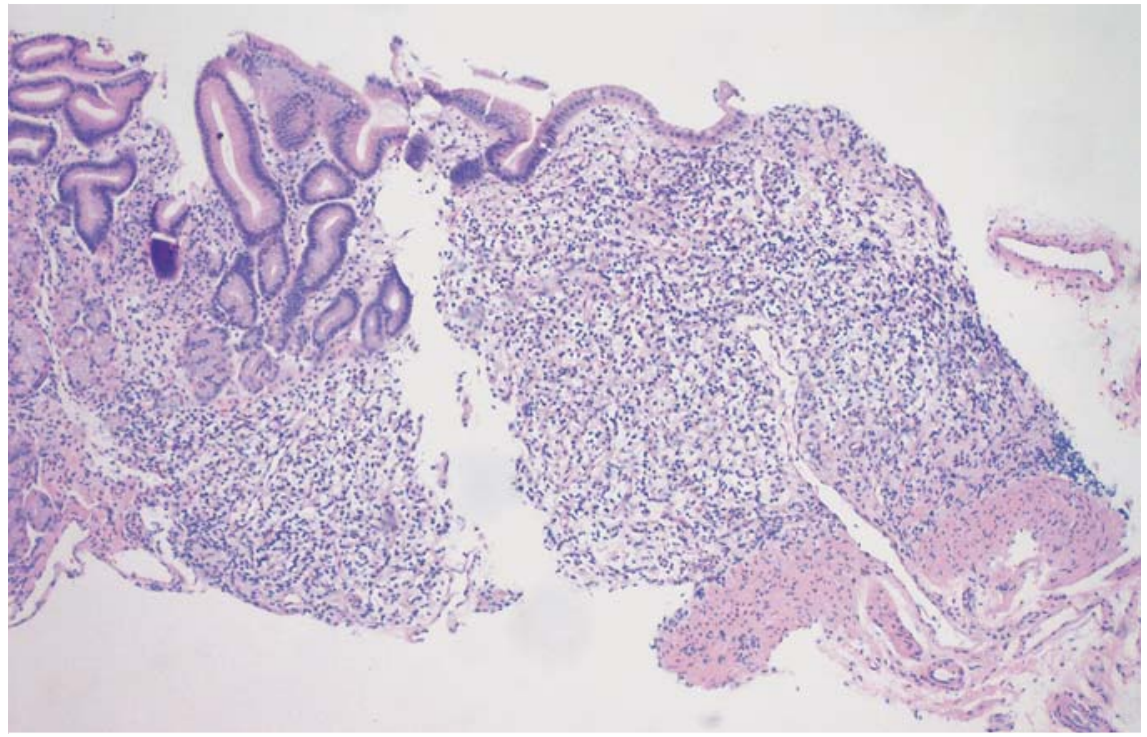

- Fig. 4 Histological examination of the gastric biopsy revealed a clear cell renal cell carcinoma growing underneath the gastric mucosa.

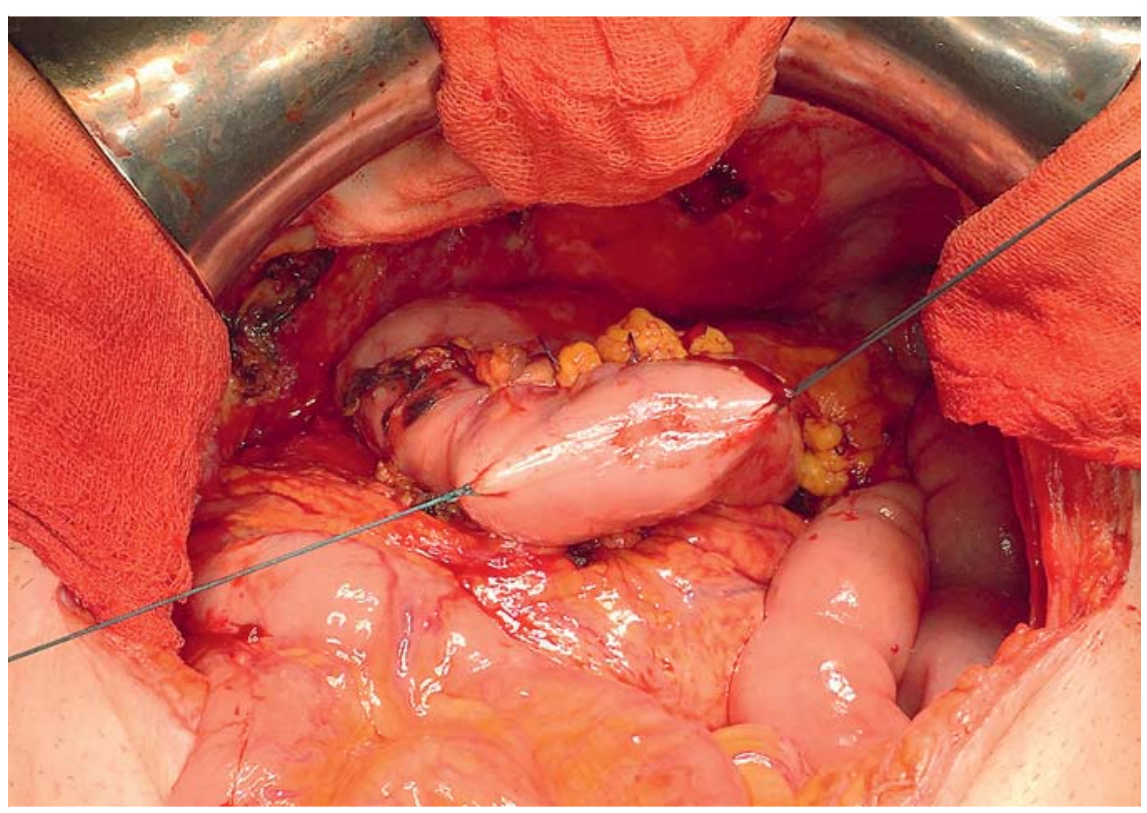

- Fig. 5 Intraoperative image during the gastric wedge resection showed the renal cell carcinoma metastasis caused by needle tract seeding.

although uncommon, is a serious adverse event that may impair patient's outcome [3]. Considering the associated risk, EUS-guided fine-needle biopsy should be carried out only when the results obtained are useful for therapeutic decision-making [4], and the needle tract line should be placed within the surgical resection margins.
The authors declare that they have no conflict of interest.
The authors

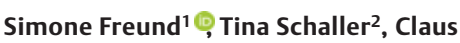

Schöler ${ }^{3}$, Helmut Messmann ${ }^{1}$, Stefan K.

Gölder ${ }^{1}$

1 Department of Gastroenterology, University Hospital Augsburg, Germany

2 Institute of Pathology, University Hospital Augsburg, Germany

3 Department of General, Visceral and Transplantation Surgery, University Hospital Augsburg, Germany

Corresponding author

\section{Simone Freund, MD}

Department of Gastroenterology,

University Hospital Augsburg, Stenglinstr. 2, 86156 Augsburg, Germany

simone.freund@uk-augsburg.de

\section{References}

[1] Adsay NV, Andea A, Basturk O et al. Secondary tumors of the pancreas: an analysis of a surgical and autopsy database and review of the literature. Virchows Archiv 2004; 444: 527-535

[2] Smith AL, Odronic SI, Springer BS et al. Solid tumor metastases to the pancreas diagnosed by FNA: a single-institution experience and review of the literature. Cancer Cytopathol 2015; 123: 347-355

[3] Minaga K, Takenaka M, Katanuma A et al. Needle tract seeding: an overlooked rare complication of endoscopic ultrasoundguided fine-needle aspiration. Oncology 2017; 93: 107-112

[4] Fujii LL, Levy M]. Basic techniques in endoscopic ultrasound-guided fine needle aspiration for solid lesions: adverse events and avoiding them. Endosc Ultrasound 2014; 3 : 35-45

Bibliography

Endoscopy 2022; 54: E380-E381

DOI 10.1055/a-1541-7061

ISSN 0013-726X

published online 9.8.2021

(C) 2021. Thieme. All rights reserved.

Georg Thieme Verlag KG, Rüdigerstraße 14,

70469 Stuttgart, Germany 